\title{
Student Teachers Help Student Teachers: A Phenomenological Study on the Student Teaching Triad's Lived Experiences
}

\author{
Hsiu-Lien Lu \\ Department of Education and Learning Technology, National Tsing Hua University, Hsinchu, Taiwan
}

\section{Email address:}

hllu@mx.nthu.edu.tw

\section{To cite this article:}

Hsiu-Lien Lu. Student Teachers Help Student Teachers: A Phenomenological Study on the Student Teaching Triad's Lived Experiences. Teacher Education and Curriculum Studies. Vol. 5, No. 4, 2020, pp. 146-155. doi: 10.11648/j.tecs.20200504.11

Received: October 12, 2020; Accepted: November 2, 2020; Published: November 11, 2020

\begin{abstract}
The phenomenological study investigated peer coaching (student teachers helping student teachers) based on the experiences of the student teaching triads, namely, student teachers, program supervisors, and mentor teachers, in a teacher education program in North America. The program recruited students who had graduated from undergraduate and completed required prerequisite courses or minored in education. A total of 69 students enrolled in the program and were randomly assigned in four cohorts. Altogether 23 stakeholders from each cohort including eight student teachers, eight program supervisors, and seven mentor teachers participated in the study and answered the guiding inquiry question: How do you perceive peer coaching in student teaching. Each participant received two recorded 90-minute in-depth interviews. Grounded theory using open coding, selective coding and axial coding strategies was employed to analyze the verbatim data sets. Five analogies consisting of a two-way street, a reality check, a pep rally, a contorted mirror, and a chore emerged and were identified during the analysis course and were utilized as themes to respond to the research question. The study revealed the complexity of peer coaching in the field and found that peer coaching brings forth advantages and problems due to the specific context the program situated. On the one hand, peer coaching creates opportunities that promote student teachers in learning to teach and teaching to learn academically and psychologically, as well as getting support emotionally. Also, peer coaching provides opportunities for student teachers to view fellow student teachers teach, which permits them to objectively reflect and assess their own performance. Furthermore, peer coaching is a time for student teachers to encourage and appreciate each other, which makes them feel more comfortable, truthful, related, and connected. Additionally, peer coaching brings about positive and potentially lasting effects to student teaching that may promise the continuum of teacher education. On the other hand, student teachers may experience problems taking notes and providing feedback due to lack of experience teaching. In addition, peer coaching may turn into a routine for student teachers to complete and check off with time constraints caused by the fast-track setup of the program. Therefore, the study suggests that teacher educators who consider adopting peer coaching assess their capacity and evaluate its feasibility based on the context they are in.
\end{abstract}

Keywords: Peer Coaching, The Student Teaching Triad, Student Teaching, Field Experience, Preservice Teacher Education, A Phenomenological Study

\section{Introduction}

Peer coaching provides a mechanism that allows student teachers to help student teachers and develop professionally $[15,27,34]$. Student teaching is a period that requires student teachers to leave behind their comfort zone being students on campus, to face the teaching reality, and to assume the role as a second teacher in the classroom. To provide preservice teachers with an additional layer of help, peer coaching is embraced with the notion that it is a nonthreatening strategy during this stage of professional development [20, 27, 34].

Student teaching is a critical stage when student teachers learn to integrate theory and practice and try to figure out what things mean in the classroom [13]. The student teaching triad, namely the student teacher, the mentor teacher, and the program supervisor, thus, is formed to respond to the need of 
student teachers [28]. Under the triad model, student teachers reside in a passive stance being supervised, observed, and provided with opinions.

Peer coaching on the other hand places student teachers in a different position and pushes them to become active learners in the setting [26, 27]. Peer coaching provides student teachers with the opportunity to observe peers, to interact with and learn from each other and is found to impact student teaching in multiple ways. First, it helps student teachers learn and become better teachers when they exchange ideas and talk with peers academically [1, 18]. Further, peer coaching helps reduce tension and fear being a student teacher in the field [10]. Finally, peer coaching helps promote student teachers' professional attitudes [3, 35, 40, 41] as well as self-efficacy with a coach perspective [12, 28]. On the other hand, peer coaching also ushers in some problems, such as increased workload, lack of skills to analyze data and provide feedback [24, 35].

Literature on peer coaching indicates that most peer coaching projects involve pre-service teachers as primary and exclusive participants in studies [27], with few including other stakeholders such as supervisors [1]. Consequently, a concern is raised about a research design that excludes as major participants other stakeholders in the field, such as mentor teachers and program supervisors, because a study with such design might not be able to illustrate the complete picture of peer coaching in student teaching. The purpose of this study, therefore, is to investigate the phenomena existing in the student teaching triad as they collaboratively assume the coaching responsibility. For the purpose, the guiding inquiry question is: How do the student teaching triad perceive peer coaching in student teaching?

\section{Relevant Literature Reviewed}

\subsection{Constructivist Learning Theory and Peer Coaching}

The theoretical framework that supports peer coaching is rooted in the constructivist learning theory. Constructivism is based on the concepts that human learning has to link prior knowledge and is actively constructed as learners who socially interact in the facilitated learning environment and constantly self-reflect upon and make sense of the interactions [16, 17]. Based on the notions, according to Hoover [17], learners assume active roles in building knowledge, instead of being transmitted. Most importantly, the learning is built upon the understandings that learners already know. In the mechanism of peer coaching, student teachers' role shifts from receiving knowledge to facilitating learning activities with peers, which allows student teachers to cognitively participate in figuring things out. Constructivist learning theory frames that peer coaching is a learning situation that facilitates preservice teachers to actively engage in planning, teaching, and critical reflection working with types of coaches. Therefore, peer coaching provides an opportunity that instigates student teachers to be actively involved and self-regulated in the entire learning process.

\subsection{The Evolution of Peer Coaching}

Peer coaching allows peers to help peers and is used widely in the education sector, such as in the classroom, in the initial teacher education and in supporting postgraduate students [15], and is recommended as a worthwhile strategy in training professionals $[1,15]$. Nonetheless, peer coaching did not take the stage in in-service teacher education until the 1980s [6]. Inspired by in-service teacher professional development $[20,22]$, teacher educators swiftly paid attention to peer coaching based on the postulation that peer coaching provides an opportunity for student teachers to participate in a coaching process that offers an opportunity to view learning to teach from a different perspective, in addition to the fact that it is cost effective [21].

\subsection{Advantages of Peer Coaching}

Peer coaching is reported to be beneficial to student teaching in many ways. For example, Alsaleh, Alabdulhadi, and Alrwaished [1] examined with 12 preservice teachers and 6 supervisors the impact of peer coaching on student teachers' professional development. They reported that peer coaching fostered teachers' professional growth and teachers' self-confidence, enthusiasm, and autonomy. Specifically, peer coaching helps student teachers learn academically and become a better teacher. Jenkins, Garn and Jenkins (2005), investigating teacher knowledge exhibited by 8 student teachers during peer coaching, reported that, while the teachers focus on management techniques, the coaches immediately extend their attention to student learning because the role as a coach allows them the time and space needed to identify other aspects of the lesson. Other studies found that student teachers are able to implement an educational innovation with special needs students through peer coaching [29] and to provide more instructionally relevant feedback to their partners [24, 29]. Further, Gemmell [10] found that peer coaching helps increase reflective opportunities, encourage inquiry, and engage student teachers in focused observation and data collection. Finally, surveying all 88 student teachers in a k- 6 teacher education program on their perceptions of the impact of peer coaching, $\mathrm{Lu}$ [26] reported that peer coaching enables practicum to become a site for active learning because this experience warrants active assessment on how they integrate theory into practice through working with peers. Some researchers find that peer coaching is just as effective as the program supervisors [36].

Further, peer coaching helps support student teachers emotionally [10]. Anderson, Caswell and Hayes [2], exploring 34 students' feedback on lesson observations by a professor and peer coaches using survey and student journals, reported that student teachers feel more relaxed observed by a peer than the professor and that they enjoy peer coaching sessions which they believe provide valuable opportunities to learn from each other. More studies document affective support of peer coaching. Kurtts and Levin [24], examining 
the impact of peer coaching on reflection and collegial support among 27 student teachers in the field, found that through peer coaching students feel less intimidated during observation and develop self-confidence. Surveying the perceptions regarding the effects of peer coaching of 52 preservice teachers, 12 program supervisors, and 50 mentor teachers in a teacher education program, $\mathrm{Lu}$ [28] reported that the group of preservice teachers is significantly more helpful than the other two groups in the area of emotional needs.

Finally, peer coaching helps promote student teachers' professional attitudes. Ovens [35], investigating a four-week alternative approach to practicum based on peer coaching and action research in New Zealand with 12 elementary students, reported that peer coaching encourages student teachers to become more accountable and committed and creates a supportive and collaborative context for teacher development. Gemmell [10], evaluating the efficacy of the peer coaching process in student teachers' collaboration, reflection, and instruction with 10 student teachers, found that in addition to developing collaboration and collegiality, peer coaching helps enhance the functions of program supervisors and mentor teachers and promote interaction with peers.

\subsection{Training of Peer Coaching Prior to Implementation}

Studies indicate that educational programs generally incorporate training prior to peer coaching [8, 27, 31]. Nonetheless, training protocols vary from program to program. Most training involves introduction to peer coaching, basic skills of data collection, and providing feedback $[2,4,10]$ through face-to-face workshops, training programs or through email, text, and other synchronized communication forms such as Skype [15].

Effects of training on peer coaching are noticeable. Literature reports that with training student teachers are found to improve ability in focused teaching skills and pedagogical reasoning and action and demonstrate better attitude towards the field experience [4, 10, 14]. It is important to facilitate training before peer coaching to develop mutual trust and respect among student teachers [15].

\subsection{Problems of Peer Coaching in the Literature}

While peer coaching is beneficial, it also yields some challenges. For example, Kurtts and Levin [24] reported that student teachers might have trouble finding time to schedule peer coaching, having less-effective partners, and lacking the skills to provide feedback due to their youth in the profession. In Ovens's study [35], they used peer coaching to structure practicum but did not provide training to student teachers. Consequently, student teachers also reported difficulties: they had increased workload; the program was poorly organized; the time in school was short, and they lacked the skills to analyze lessons. With the problems revealed in Kurtts and Levin's and Ovens's studies, it may suggest that time, workload, skills, and program organization are the four major problems facing peer coaching in teacher education.

\section{Method}

This study utilized a qualitative phenomenological approach, of which the core interest is to examine and understand the reality in the fields that the student teaching triads experience, describe, and interpret [9, 32, 38]. Phenomenology is an inquiry method based on the premise that the reality of an entity is co-constructed by the goals and purposes of the institution and the ways individual people working in the context interpret and put their responsibilities into practice $[32,39]$. Based on this method, this study pursued an in-depth understanding of ways the student teaching triad perceived and interpreted peer coaching events and their interactions with the events in the field experience [9]. The purpose of obtaining the understanding was to better depict the multi-facets and complexity of the student teaching triads' lived experiences in the specific setting under the specific peer coaching circumstance [39].

\subsection{Study Setting and Intervention}

The study took place in a fifth-year master's k-6 teacher education program in a Northeastern state in the United States. The program recruited students graduated from undergraduate and completed required prerequisite courses or minored in education. A total of 69 students enrolled in the program and were randomly assigned in four cohorts. Each cohort had one Head Teaching Assistant (Head TA) in charge to support the field experiences, including tracking, problem solving, and advising the compilation of a portfolio for the licensure purpose, in 90-minute bi-weekly seminars. They took and finished coursework on campus and field experiences in classrooms during the one-year time span.

To diversify field experiences, students were placed in different classrooms in different social economic status districts for the two semesters. The districts located in urban, suburban, and rural areas within a 40-mile radius around the university. The field experiences included pre-practicum and practicum for the first and second semester, respectively. Students worked in the classroom three days a week for prepracticum and five full days a week for practicum, with a total of approximately 900 hours in the field. After successfully completing the intensive teacher education, students obtain a master's degree and a teacher's license.

The supervisory model of the program encompassed peer coaching in conjunction with the traditional supervision of the program supervisor and the mentor teacher. Traditionally, student teaching is supervised by the program supervisor and the mentor teacher. Nonetheless, in addition to two observations provided by each of the mentor teacher and the program supervisor every semester, student teachers received two peer observations from fellow student teachers as well. They could choose their own partners who student taught in their school or another school. Subsequently, some selected those who they knew well in any cohort; others picked someone out of convenience. 
To facilitate peer coaching, the program provided some basic training. To begin with, students were informed of the supervisory components and received an overview of what peer coaching looked like and how to use observation tools by going over the information in the program package during a two-hour orientation in the beginning of the school year. Second, each cohort was assigned a Head TA who held a biweekly seminar with student teachers to support their field experiences, collected and reviewed their peer coaching reports. Third, student teachers purchased a program package in which there was a set of prompts to use when conducting pre and post conferences and they had the same observation tools used by program supervisors and mentor teachers. Fourth, program supervisors informally provided support when needed. Finally, student teachers were to learn from seeing how program supervisors and mentor teachers observed them.

In each peer observation, student teachers maintained the three-step observation procedure illustrated in the program package. They first conducted a pre-conference where the peer teacher shared the goals of the lesson and the observation tool to collect data on. While the peer teacher was teaching, the peer coach, then, collected data using the selected observation tool and took notes for what he/she observed. Finally, they convened and used the data to reflect upon the lesson taught using the questions provided in the program package. Once they finished an observation, the peer teacher filled up a report and turned it in to the cohort Head TA for feedback. The Head TA ensured all required peer observations were completed and checked off.

\subsection{Participants}

Using purposeful sampling, the researcher recruited participants from the student teaching triads in the field. The researcher considered the following criteria when recruiting participants: a) stakeholders of different roles, b) varied field settings including urban and rural areas, and c) different cohorts, to yield a better representation of the population (Rossman \& Rallis, 2011; Seidman, 2019). With the criteria, the researcher selected 23 participants from the groups of mentor teachers $(\mathrm{n}=7$; female $=6$, male $=1)$, program supervisors $(\mathrm{n}=8$; female $=6$, male $=2)$, and student teachers $(\mathrm{n}=8$; all females). The mentor teachers were 31 years old and up, mostly taught more than 10 years, and had mentoring experiences ranging from 3 to 25 years. The student teachers were 21 to 25 years old. The program supervisors aged 30 to 55; four of them were doctoral students, three retired teachers, and one from another path of life. They each had teaching experiences of 3 to 30 years.

\subsection{Data Sources and Collection}

Semi-structured interviews with the three groups of participants were the major data sources, in addition to supplementary programmatic documents and field notes. The researcher applied varied questioning techniques to the interviewing inquiry. She first used a list of open-ended semi-structured sub-questions, guided by the overarching inquiry question tailored for each group of participants, and constantly refined it along the progress of interviewing so as to maintain consistency as well as to ensure in-depth data [30]. Then, when participants' remarks appeared vague and general, she utilized probing techniques to urge participants to explain further. An example was when a participant stated, "It was like a pep rally," a probing question would be like, "Please explain what you meant by "a pep rally." She also brought participants back for further clarification when doubts or questions arose across interviewees.

Data collection took place in the second semester of the field experience. The researcher started the interview process immediately after participants signed informed consents. The interviews employed an alternative model of in-depth interviewing procedures proposed by Seidman [39]. Instead of three interviews that address the prior, current, and post experiences relevant to the topic respectively, Seidman recommends an alternate model for the consideration of participants' availability. To maximize participation, this study used two interviews to include the three points of experiences each lasting approximately 90 minutes and audio taped. In the first interview, the researcher invited the participants to describe their prior and current experiences relevant to the topic. An interval of one week was given before the second interview and allowed the participants to reflect on what they shared and to settle emotions. The second interview allowed participants to pick up what was absent in the first interview, interpret, and make suggestions to the experiences.

With the support of cohort Lead TAs, the researcher was able to collect student artifacts. Additionally, the researcher visited a few classrooms to observe peer coaching sessions and take field notes. Lastly, other data sources, such as program package illustrating expectations and guidelines of all stakeholders, student artifacts, and field notes, were collected to enrich the description of the program as well as to triangulate the data.

\subsection{Data Analysis}

The analysis process employing the grounded theory was a progression of intellectual and laborious endeavors [5, 33]. To ensure the analysis staying genuine to what the participants mean, all interviews were verbatim transcribed. The researcher started the data analysis using the open coding, selective coding, and axial coding approach when first few data sets were completed. Following the constant comparison and contrast principle, the researcher undertook a series of continuous reading, chunking, linking, clustering, sorting, and condensing [5, 33], themes and supportive quotes therefore emerged from the process of analysis. What was special of this analysis process was that analogies that participants used to interpret their experiences were found to be useable as themes. Using the analogical themes to categorize data was helpful because they link selected data in a coherent manner. 


\section{Results}

To illustrate the results in a comprehensive and detailed manner, this division encompassed two sections: a) an overview of the analogies, b) results of the research question.

\subsection{An Overview}

Five themes emerged from the data analysis process. Table 1 is a synopsis of the thematic analogies and the numbers of participants whose remarks support the analogies.

Table 1. Thematic Analogies and Numbers of Supportive Remarks.

\begin{tabular}{|c|c|c|c|c|}
\hline Thematic Analogy & PSs $(n=8)$ & MTs $(n=7)$ & STs $(n=8)$ & Total $(\mathrm{N}=23)$ \\
\hline A two-Way Street & $6(75 \%)$ & $6(86 \%)$ & $8(100 \%)$ & $20(87 \%)$ \\
\hline A Reality Check & $6(75 \%)$ & $7(100 \%)$ & $6(75 \%)$ & $19(83 \%)$ \\
\hline A Pep Rally & $4(50 \%)$ & $7(100 \%)$ & $5(63 \%)$ & $15(65 \%)$ \\
\hline A Contorted Mirror & $4(50 \%)$ & $0(0 \%)$ & $6(75 \%)$ & $10(43 \%)$ \\
\hline A Chore & $4(50 \%)$ & $2(29 \%)$ & $3(38 \%)$ & $9(36 \%)$ \\
\hline
\end{tabular}

$\mathrm{RQ}=$ research question; $\mathrm{PSs}=$ program supervisors; $\mathrm{MTs}=$ mentor teachers; $\mathrm{STs}=$ student teachers

As shown in the above table, we can see that the thematic analogies have the connotation in the participants' daily life experiences. From the top down, a two-way street implies that peer coaching creates an avenue that allows student teachers to interact as teacher and student at the same time, instead of a one-person talk from the supervisor or the mentor teacher. A reality check implies that peer coaching provides an opportunity for student teachers to realize what is really happening in student teaching classrooms. A pep rally is a gathering of people, especially students in schools or colleges, before an event, implying that peer coaching is an event to get student teachers excited and to encourage each other to get through the experience smoothly. A contorted mirror implies that peer coaching provides twisted and not clear information to each other. Finally, a chore implies that peer coaching is like a duty that does not serve a special purpose.

Examining comprehensively, the first three analogies: a two-way street, a reality check, and a pep rally, indicated beneficial features; while the last two, a contorted mirror and a chore, suggested negative connotations of the peer coaching experience. For the most part, participants had positive experiences and believed that peer coaching was like a two-way street $(n=20,87 \%)$, a reality check $(n=19,83 \%)$, and a pep rally $(n=15,65 \%)$. On the other hand, some participants viewed the peer coaching experience as seeing into a contorted mirror $(\mathrm{n}=10,43 \%)$ and taking up a chore $(\mathrm{n}=9,36 \%)$.

Taking groups of participants apart and looking deeper, we can find that while all student teachers $(100 \%)$ perceived peer coaching as an opportunity to learn from both ways, being teacher and student; all mentor teachers (100\%) believed peer coaching allowed student teachers to obtain refreshment and affect support as indicated by the analogies of a reality check and a pep rally. Additionally, student teachers $(75 \%)$ experienced confusion from the peer coaching experience; whereas mentor teachers $(0 \%)$ were rarely aware of the problem. Half of the program supervisors $(50 \%)$ were suspicious of the peer coaching experiences and concerned that it ushered in confusion (a contorted mirror) and unnecessary work (a chore) to student teaching. Overall, mentor teachers were most optimistic and positive about peer coaching. On the other hand, while student teachers and program supervisors recognized the advantages of peer coaching, they were concerned that student teachers were not equipped to provide clear information to peers and therefore there was a concern that peer coaching might turn into a chore. Further illustrations of each analogy followed below.

\subsection{Research Question: How Do the Student Teaching Triad Perceive Peer Coaching in Student Teaching?}

The results indicated that peer coaching brings forth to student teaching experience three advantages analogized as a two-way street, a reality check, and a pep rally; and two major problems compared to a contorted mirror and a chore.

\subsubsection{A Two-Way Street}

This analogy of a two-way street pulled out the most remarks from the three groups of participants $(87 \%)$, and the group of student teachers illustrated it most specifically and vividly. This category generates four salient points: the origin of this analogy, coming with two purposes, learning as a student, and developing a coach's perspective.

The origin of this analogy. A two-way street was first analogized by CT1, who further described peer coaching as student teachers get to learn from the roles of a teacher and a student at the same time. As ST6 stated, "It's like being a teacher and a student at the same time. You learn from your peers, but you also tell them what their next steps and strengths are in the lesson. That was a way like teacher/student." Also, ST1 claimed, "It's not just one way that you get from mentor teachers and supervisors."

Coming with two purposes. Participants believed that peer coaching come with dual purposes of providing feedback and reflecting from watching peer teaching simultaneously, which develops their teaching and learning. For example, ST3 explained, "They (referring to the program) want it more for the other person that you are watching and giving them advice. But it's really very beneficial for yourself because you are giving yourself advice for what you shouldn't do, or you should or like to do it." ST8 also shared similar experience: "It's helpful for me to see different perspectives of teaching and see what they're doing. And I get to hear a different perspective on my teaching, to know what people think of different things that I'm doing in my teaching."

Learning as a student. Peer coaching allows student 
teachers to learn as students. As ST4 acknowledged, "I benefit from observing my peers teaching. It's helpful to see different perspectives of teaching and what they're doing. You get to see and compare what you're seeing in your classroom to a different classroom." Below are two further excerpts from participants:

It's almost like I am playing the role of a student. When I am watching their lesson, I try to see if I understand. So when I am teaching, I try to think outside of the box: If I have someone else watching this lesson plan, what would I do differently? (ST3)

Sometimes I say things without thinking, just complimenting them good job a million times. It's interesting to see different ways they ask students to get their attention, like all eyes are up, one two three, quiet eyes, look at the note. It was like different methods that my peers did to get attention. I can use those in my own classroom and the words. (ST1)

Developing a coach's perspective. Peer coaching promotes student teachers to develop a coach's perspective. As ST2 proclaimed, "A lot of times my peers that are coaching me notice things happening in the classroom that I don't notice." ST1 also stated, "It helps me to look at what kids are doing. There is so much you can see. People say the teacher has eyes everywhere. But honestly there are certain things you can't see as a teacher." PS1, being a program supervisor for years, recognized the advantage of this type of feedback stating, "It's nice sometimes to hear what your peer has to say about what you are doing. It might be much more of a personal level. In a lot of cases it's going to be a completely different kind of feedback that I would give to an intern."

\subsubsection{A Reality Check}

This analogy received the second most remarks from the three groups of participants $(83 \%)$. This result implies that most participants believed that peer coaching provides an opportunity for student teachers to go out in different classrooms, check for what is happening, and realize that they are not the only ones doing something. This category generates three salient points: the origin of the analogy, promoting psychological change, and having similar concerns and troubles.

The origin of the analogy. This analogy was generated from PS3's remarks. The program supervisor stated, "They (student teachers) have got to realize that they have just started out and things are not going to be as good as the professional teacher. That's very different from seeing a peer teach because it puts you on the right track. It gives you a reality check."

Promoting psychological change. Peer coaching brings forth psychological change in student teachers including thinking more critically while teaching, being more accountable, and having more respect towards program supervisors. Following were the excerpts of participants:

Peer coaching does force you to critically think about what is going on in this lesson rather than just teaching this lesson and having someone tell you what's going on.... It keeps you on your toe and makes you aware of everything else that's happening in the classroom...I guess peer coaching is about that psychological change. (ST2)

I have noticed that some student teachers began to be in charge of the class after their peers observed. Before they were very submissive, afraid of jumping in, and when their peers came to observe, they felt like I am in charge. (CT7)

When you understand other people's perspectives, you are more open and trusting of them. If you're the person who is collecting data on someone's off task behavior, you're seeing what that feels like.... I've gotten feedback from a lot of student teachers. When they have had to peer coach at it, they had more respect for what I do. It also helps them see what my role is. It defines my role a little bit more for them. (PS2)

Having similar concerns and troubles. This experience allows student teachers to realize that their concerns and troubles are similar among student teachers, which helps validate their performance. As ST3 stated, "It makes you feel better because you know that you are not the only one bad at that." ST2 echoed this feeling, "I got a lot of confidence after watching other fellow student teachers because I realized I'm where I need to be. It was extremely validating."

\subsubsection{A Pep Rally}

This analogy drew the most support from mentor teachers $(100 \%)$, whereas, with a total average of $65 \%$. This category generates four salient points: the origin of this analogy, developing connection and empathy, providing affect support, non-judgmental and non-evaluative.

The origin of this analogy. Peer coaching provides student teachers with opportunities to support each other emotionally, like s pep rally where people get together to support a sports team before a game. As CT4 stated, "It's like a pep rally before the game.... It builds their confidence, gives them a positive attitude towards things, [and] gets everyone head side up for the big game.... They felt it more as an emotional support." PS7 agreed with this idea stating, "Peer coaching is a valuable and important thing... They had a lot of interaction learning from each other. It's just like they were assigned to hang out."

Developing connection and empathy. Peer coaching allows student teachers to develop connection and empathy. As CT5 stated, "It's like with a good buddy that you go out [with] and talk about things." CT1 asserted that "peer coach is like someone who really knows what you are going through but has her own load to carry. So, she has empathy." The empathy developed among student teachers "allows them to relate more and connect more," echoed PS4.

Providing affect support. Peer coaching provides specific opportunities for student teachers to get together, talk about teaching, and support each other. As ST8 contended, "I actually feel more comfortable. We spend time together in classes and everything else that we do. It's a friend who is helping, who's giving feedback about my teaching." ST1 shared her experience when peers came observing from a different school. She stated, "I showed her the gym, the 
science, and the libraries in a different building.... I like having peers observe me.... You can talk about what's bothering you. It's more relaxing talking to your peer."

Peer coaching provides emotional support. As ST2 affirmed,

The main thing was the emotional support. It's easier for a peer to observe you, a) because they are in your school setting; b) they are more familiar with your school setting. So, they may have more relevant advice to give you as opposed to the abstract advice that I had [from] a program supervisor [who] wasn't fully aware of this school system and how this school works. One peer came and observed me. I came and observed her. We both had a lot of issues with just no attention span in the classroom and the students having a hard time concentrating, just in general disrespectful behavior. So, we give each other advice about how to deal with that.

Non-judgmental and non-evaluative. Peer coaching was non-judgmental, non-evaluative, with mutual understanding, and to support each other, while peers shared ideas and thoughts about the experience. As CT6 stated, that "it's not judgmental. It's just for the information of the person that you are coaching. That is on an equal basis and you are just looking to see how you can improve or help that person. You are just there to help them like solve a problem at their own level." CT2 also contended that "it's another opportunity for observation and a more intimate, relaxed guard down, kind of from the guard change to share some thoughts and ideas, but a little bit more honest and open, a little rawer." Following were excerpts of two student teachers:

We are not evaluating. We all know that we have our good quality and we have our bad quality. We are aware that we are not all the best teachers, that we are not smart in everything. We share with each other and work with each other. (ST5)

They're not grading me or evaluating me. So, I do feel more comfortable because they don't have such experience and I know they're not going to be all over me about little things. They don't have as much credential as the program supervisor so maybe that's why I'm not as nervous because I know they're not going to be judging me as harshly. (ST8)

ST1's remarks helped conclude this section: "I like talking about my lessons to a peer. They are in the same boat as me.... So, I feel like I am more truthful in peers."

\subsubsection{A Contorted Mirror}

This analogy of a contorted mirror pulled out 10 participants (43\%) with six out of eight student teachers and four out of eight program supervisors, but no mentor teachers having any connection with the analogy. This category generates three salient points: the origin of this analogy, lack of appropriate training, and inexperience in teaching.

The origin of this analogy. ST2's remarks below nicely explicated this analogy: "Being observed by a peer is like looking in a contorted mirror, a mirror that is a little wavy. They do their best to tell you what happened. But it won't be exactly the way it happened." This analogy implied that with little experience and training, given that peer coaches tried hard, they still could not provide clear feedback to peer teachers.

Lack of appropriate peer coaching training. One of the reasons why student teachers viewed peer coaching as a contorted mirror was because they lacked appropriate training and knew little regarding how to perform peer coaching. PS4 reasoned the problem by stating, "They weren't prepared in the sense that they were given a handbook and at the same time they were going into the classrooms. They were doing a peer observation without really understanding on it." ST7 had a negative experience from this lack of preparation. She described, "I had a peer. She wrote in an observation of me that the lesson was not organized and chaotic. It would be more effective to have the factual data." PS3 articulated her insight, "It's very difficult to be a peer coach. If you say anything negative, or that might be supportive criticism, but your peer might look at this criticism. It might be taken too personal." PS4 noticed this problem and argued her point, "They're not specific with their feedback. This is with very little instruction on how to do peer coaching, very little instruction." The findings indicated that without appropriate training from the program, peer coaching could bring forth some problems.

Inexperience in teaching. Inexperience in teaching is another reason for a contorted experience. As ST7 questioned her experience, "How can we coach through this because I am inexperienced as you are, whereas you are inexperienced as I am? To me it's not an effective process because we cannot figure out ourselves too." ST2 also argued, "The peer doesn't have the experience to draw on. They don't necessarily know what they're looking at or looking for." PS6 stated, "Right now the feedback I'm seeing is very general. A lot of it is because they haven't had much experience in the classroom themselves."

\subsubsection{A Chore}

This analogy of a chore pulled out the least remarks from the three groups of participants $(36 \%)$; however, it provided crucial information of what happened in peer coaching. This category generates two salient points: the origin of this analogy and lack of time.

The origin of this analogy. Peer coaching in this program has become "a chore," as ST2 put it, because of its time constraints. ST4 agreed and further explained it: "We are so busy that it's like another thing on the plate." ST3 echoed the reason: "Peer coaching is something you have to do. So, someone has to observe you and you have to observe someone else."

Lack of time. Time constraint was the major issue facing the practice of peer coaching. Time constraint came from the fact that it was a short ten-month program. PS6 and PS4 believed that the issue resulting from the lack of time in this program and therefore "it's just one more thing they have to do on their plate." CT1 described what she saw in the classroom: "This peer coaching thing right now for many of them is like just one of these things they have got to check 
off their list." PS5 illustrated her observation,

I have been in a classroom a few times when a peer is observing. Many times, there was utter chaos going on at that time in a classroom. But that peer had made time in her busy schedule to be there, was not going to reschedule it, so that they could get their peer observation assignment done.

CT5 viewed the problem with understanding. She stated, "It's going to be an issue no matter what. I mean that's just a ten-month program with certification and a master's degree and not assuming any prior course work in education."

\section{Discussion}

The findings of the inquiry question reveal two sides of impact stemming from peer coaching. On the one hand, the student teaching triad considered peer coaching to be overwhelmingly beneficial, as indicated by the three analogies, a two-way street, a reality check, and a pep rally. On the other hand, the findings indicate that three factors, namely, inexperience of teaching, lack of adequate training, and lack of time, triggered the problems to occur, as indicated in the analogies of a contorted mirror and a chore.

\subsection{Benefits of Student Teachers Helping Student Teachers}

Most of the participants agreed that peer coaching creates opportunities that promote student teachers in learning to teach and teaching to learn academically and psychologically $[10,27,29]$, as well as getting support emotionally [1, 24, 28]. Peer coaching is found to serve dual purposes and promote student teachers to learn from two roles, being a student and a teacher at the same time. On the one hand, peer coaching urges student teachers to learn as students when watching peers teach and reflecting upon their own teaching; simultaneously peer coaching positions student teachers as a coach, where they view teaching from a different stance [26]. This two-way experience is empowering to student teachers and precious to preservice teacher education as it transforms the practicum experience from passively receiving comments from experts to actively providing feedback, reflecting upon teaching, and improving teaching [1, 23]. This result confirms literature findings that peer coaching promotes practicum as a site for active learning $[10,26]$.

Further, peer coaching provides opportunities for student teachers to view fellow student teachers teach, which permits them to objectively reflect and assess their own performance. This reality check, according to the results, helps validate their performance and develop their confidence in the classroom [24]. The results also indicate that student teachers develop understanding about supervision and positive attitude towards program supervisors through this experience, which is consistent with the literature that peer coaching helps foster relationships in the field learning community [26].

Additionally, peer coaching is a time for student teachers to encourage and appreciate each other as if in a pep rally that makes them feel more comfortable, truthful, related, and connected [1, 26, 35]. Additionally, the findings indicate that peer coaching provides opportunities specified for student teachers to communicate about teaching, a behavior of collegiality that could be potentially beneficial to a constructive in-service learning community [11, 40].

It is inferable based on the results that peer coaching brings about positive and potentially lasting effects to student teaching that may promise the continuum of teacher education [7]. Interested in teacher induction, FeimanNemser argues that preservice teacher education should help preservice teachers form habits and skills that are necessary for the ongoing teaching in the company of colleagues. She posits that serious conversation with colleagues concentrating on teaching ensures continuous learning in the profession. Peer coaching, opportunities designated for student teachers to share teaching and learning with colleagues following structured observation strategies, helps preservice teachers form the habits and skills needed for continuous development in the profession in the company with colleagues.

\subsection{Factors that Trigger Problems}

Findings indicate some obstacles student teachers experienced, such as problems taking notes and providing feedback due to lack of experience teaching. The problem confirms the literature that student teachers lack skills to provide feedback [24] or analyze feedback [35]. Truly, inexperience in teaching and lacking skills in peer coaching are inherent and justifiable weaknesses of student teachers. However, the lack of adequate training undoubtedly inevitably increases the likelihood for the above problems to occur. In considering the wellbeing of student teachers, the reality regarding student teachers' having little base to conduct observations and conference has seriously violated the fundamental principle of supervision and coaching [11]. Factually, literature has reported that, when modeled how to observe and being able to practice, student teachers know what to look for and how to facilitate feedback [10, 25]. The results may serve as a reminder to teacher educators of the necessity of training preceding the practice of peer coaching [27].

Finally, one critical factor that turns peer coaching into a chore, a waste of time, is time constraints. For an intensive program that has only a ten-month duration, the inclusion of peer coaching might cause more problems than advantages because student teachers rarely have time to attend to it. Therefore, for a fast-track program, student teaching without peer coaching might better serve the purpose. With this being discussed, nonetheless, in considering all the potential values indicated in this study, for a program with a longer duration, say two years or so, where there is room for student teachers to receive training and practice at a reasonable pace, peer coaching might be a beneficial addition.

\subsection{Contributions of the Study}

Contributions of this study to the literature of peer coaching were manifold. First, it involved participants from the pool of stakeholders in the field, which allowed to 
portrait the collective perceptions of peer coaching and thus more fully reflected the reality. Second, it utilized unique analogies generated from interview data to illustrate the impact of peer coaching. More importantly, each analogy captured certain essence and together they illustrated the reality of peer coaching in a program under the circumstances that it had a short time span and did not provide adequate training. Finally, the study context was a regular teacher education program, a rare case in peer coaching literature, as pointed out by $\mathrm{Lu}$ [27].

\subsection{Recommendation}

The study reveals the complexity of peer coaching in the field and suggests that teacher educators who consider adopting peer coaching assess their capacity in time and training provision and evaluate its feasibility based on the context they are in.

\section{Conclusion}

To sum up, the study indicates that peer coaching provides an opportunity for student teachers to link prior knowledge and is actively constructed their understanding with practice by means of interacting with peers in the student teaching setting and via constant self-reflecting upon and making sense of the interactions regarding student teaching $[16,17]$. This type of experiences fosters student teachers' development in emotional and academic aspects, which could potentially help extend student teachers' learning beyond the field experience. This study, therefore, indirectly points future research towards longitudinal studies on the long-term impact of peer coaching in the progression of teacher education. The study also indicates undesired impact of peer coaching stemming from not having adequate training, which leads to a suggestion that future studies explore the extent of training needed for peer coaching to be successful. Finally, having enough time is a critical factor to consider before a program espouses peer coaching as an additional component to student teaching.

\section{References}

[1] Alsaleh, A., Alabdulhadi, M., \& Alrwaished, N. (2017). Impact of peer coaching strategy on pre-service teachers' professional development growth in Kuwait. International Journal of Educational Research, 86, 36-49.

[2] Anderson, N. A., Caswell, I. J., \& Hayes, M. E. (1994). Using peer coaching to provide additional feedback to preservice teachers of reading in an early field experience. In Sturtevant \& Linek (Eds.), Pathways for literacy: Learners teach and teachers learn. Pittsburgh, KS: College Reading Association.

[3] Benedetti, T. A., \& Reed, M. K. (1998). Supervising student teachers using peer coaching. Paper presented at the Annual Meeting of the National Council of Teachers of Mathematics, Washington, DC.

[4] Bowman, B. L., \& McCormick, S. (2000). Comparison of peer coaching versus traditional supervision effects. The Journal of Educational Research, 93 (4), 256-261.

[5] Corbin, J., \& Strauss, A. (2007). Basics of qualitative research: Techniques and procedures for developing grounded theory. Thousand Oaks, California: Sage publications, Inc.

[6] Englert, C. S., \& Sugai, G. (1983). Teacher training: Improving trainee performance through peer observation system technology. Teacher Education and Special Education, 6, 7-17.

[7] Feiman-Nemser, S. (2001). From preparation to practice: designing a continuum to strengthen and sustain teaching. Teachers College Record, 103 (6), 1013-1055.

[8] Fryab, J. M., \& Koh, T. H. M. (2006). Peer coaching with interactive wireless technology between student teachers: Satisfaction with role and communication. In Interactive Learning Environments: Routledge.

[9] Gay, L. R., \& Airasian, P. (2008). Educational research: Competencies for analysis and applications. (9th ed.). Columbus, Ohio: Upper Saddle River, New Jersey.

[10] Gemmell, J. C. (2003). Building a professional learning community in preservice teacher education: Peer coaching and video analysis. (Dissertation), University of Massachusetts, Amherst.

[11] Glickman, C. D., Gordon, S. P., \& Ross-Gordon, J. M. (2017). SuperVision and instructional leadership: A developmental approach (6th ed.). Boston, MA: Pearson Education, Inc.

[12] Goker, S. D. (2005). Impact of peer coaching on self-efficacy and instructional skills in TEFL teacher education. Science Direct, 34, 239-254.

[13] Goodnough, K., Osmond, P., Dibbon, D., Glassman, M., \& Stevens, K. (2009). Exploring a triad model of student teaching: Pre-service teacher and cooperating teacher perceptions. Teaching \& Teacher Education, 25, 285-296.

[14] Hasbrouck, j. E. (1997). Mediated peer coaching for training preservice teachers. The Journal of Special Education, 31 (2), 251-271.

[15] Hooker, T. (2013). Peer coaching: A review of the literature. Waikato Journal of Education, 18 (2), 129-139.

[16] Hoover, W. A. (1996). Constructivism. SEDL Letter, IX.

[17] Huitt, W. (2009). Constructivism. Educational Psychology Interactive. Valdosta State University, Valdosta. GA.

[18] Jenkins, J. M., Garn, A., \& Jenkins, P. (2005). Preservice Teacher Observations in Peer Coaching. Journal of Teaching in Physical Education, 24 (1), 2.

[19] Jenkins, J. M., \& Veal, M. L. (2002). Preservice teachers' PCK development during peer coaching. Journal of Teaching in Physical Education, 22, 49-68.

[20] Joyce, B., \& Showers, B. (1980). Improving inservice training: The messages of research. Educational leadership, February, 379-385.

[21] Joyce, B., \& Showers, B. (1987). Low-cost arrangements for peer-coaching. Journal of Staff Development, 8 (1), 22-24.

[22] Joyce, B., \& Showers, B. (1995). The design of training and peer coaching. In Student achievement through staff development. White Plains, NY: Longman. 
[23] Kohler, F. W., McCullough, K. M., \& Buchan, K. A. (1995) Using peer coaching to enhance preschool teachers' development and refinement of classroom activities. Early Education \& development, 6 (3), 215-239.

[24] Kurtts, S. A., \& Levin, B. B. (2000). Using peer coaching with preservice teachers to develop reflective practice and collegial support. Teaching Education, 11 (3), 297-310.

[25] Lam, R. (2010). A Peer Review Training Workshop: Coaching Students to Give and Evaluate Peer Feedback. TESL Canada Journal, 27 (2), 114-127.

[26] Lu, H.-L. (2009). Joint effects of peer coaching and the student teaching triad: Perceptions of student teachers. Southeastern Teacher Education Journal, 2 (2), 7-18.

[27] Lu, H.-L. (2010). Research on Peer Coaching in Preservice Teacher Education - A Review of Literature. Teaching and Teacher Education, 26 (4), 748-753.

[28] Lu, H.-L. (2014). Collaborative Effects of Cooperating Teachers, University Supervisors, and Peer Coaches in Preservice Teachers' Field Experiences. Journal of Educational Research and Development, 10 (1), 1-22.

[29] Mallette, B., Mabeady, L., \& Harper, G. F. (1999). The effects of reciprocal peer coaching on preservice general educators' instruction of students with special learning needs. Teacher Education and Special Education, 22 (4), 201-216.

[30] Maxwell, J. A. (2013). Qualitative research design: An interactive approach (3rd ed.). Thousand Oaks, CA: SAGE.

[31] McAllister, E. A., \& Neubert, G. A. (1995). New teachers helping new teachers: Preservice peer coaching. Bloomington, IN: ERIC Clearinghouse on Reading, English, and Communication.

[32] Mertens, D. M. (2004). Research methods in education and psychology: Integrating diversity with quantitative, qualitative, and mixed methods. Thousand Oaks, California: Sage.

[33] Miles, M. B., \& Huberman, A. M. (2019). Qualitative data analysis (4th). Thousand Oaks, California: Sage Publications.

[34] Neubert, C. A., \& McAllister, E. (1993). Peer coaching in preservice education. Teacher Education Quarterly, Fall, 7784.

[35] Ovens, A. (2004). Using peer coaching and action research to structure the practicum: An analysis of student teacher perceptions. Journal of Physical Education New Zealand, 37 (1), 45-60.

[36] Pierce, T., \& Miller, S. P. (1994). Using peer coaching in preservice practica. Teacher Education and Special Education, 17 (4), 215-223.

[37] Rice, G. (2012). Formative dialogues in teaching nonthreatening peer coaching. The Journal of chiropractic education, 26 (1), 62-67. Retrieved from https://doi.org/10.7899/1042-5055-26.1.62

[38] Rossman, G. B., \& Rallis, S. F. (2011). Learning in the field and introduction to qualitative research (3rd). Thousand Oaks, California: SAGE Publications.

[39] Seidman, S. (2019). Interviewing as qualitative research: A guide for researchers in education and the social sciences (5th ed.). New York: Teachers College Press.

[40] Slater, C. L., \& Simmons, D. L. (2001). The design and implementation of a peer coaching program. American Secondary Education, 29 (3), 67-76.

[41] Weiss, E. M., \& Weiss, S. G. (1998). New directions in teacher evaluation. ERIC DIGEST (Washington, DC, ERIC Clearinghouse on Teaching and Teacher Education, AACTE). 